\title{
Stabilization of autotransplanted teeth using thermoplastic retainers
}

\author{
Muhammed İsa-Kara ${ }^{1}$, Fatih Sarı ${ }^{2}$, Mehmet Emre-Coşkun ${ }^{2}$, Alper Kuştarcı ${ }^{3}$, Hidayet Burak-Polat ${ }^{4}$, Hakan \\ Özdemir ${ }^{5}$, Serkan Polat ${ }^{6}$
}

\author{
${ }^{1}$ DDS, PhD, Assistant Professor, Department of Oral and Maxillofacial Surgery, Gaziantep University, Faculty of Dentistry, \\ Gaziantep, Turkey \\ ${ }^{2}$ DDS, Research Assistant, Department of Prosthodontics, Cumhuriyet University, Faculty of Dentistry, Sivas, Turkey \\ ${ }^{3}$ DDS, PhD, Assistant Professor, Department of Endodontics, Cumhuriyet University, Faculty of Dentistry, Sivas, Turkey \\ ${ }^{4}$ DDS, PhD, Private Dentist, Kayseri, Turkey \\ ${ }^{5} \mathrm{DDS}, \mathrm{PhD}$, Assistant Professor, Department of Periodontology, Cumhuriyet University, Faculty of Dentistry, Sivas, Turkey \\ ${ }^{6} \mathrm{DDS}, \mathrm{PhD}$, Associate Professor, Department of Oral and Maxillofacial Surgery, İnönü University, Faculty of Dentistry, Mala- \\ tya, Turkey
}

Correspondence:

Gaziantep University Faculty of Dentistry

27070, Gaziantep, Turkey

phismer@yahoo.com Isa-Kara M, Sari F, Emre-Coşkun M, Kuştarcı A, Burak-Polat H, Özdemir
H, Polat S. Stabilization of autotransplanted teeth using thermoplastic re-
tainers. Med Oral Patol Oral Cir Bucal. 2011 May 1;16 (3):e369-75.
http://www.medicinaoral.com/medoralfree01/v16i3/medoralv16i3p369.pdf
Received: $21 / 05 / 2010$ Accepted: 26/08/2010

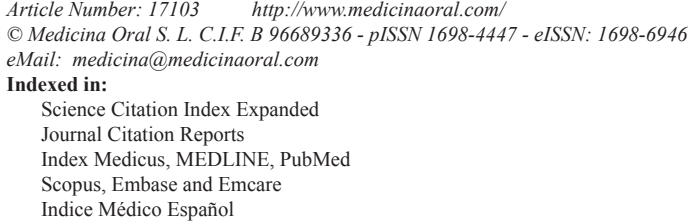

\begin{abstract}
Objective: Different fixation techniques have been used for stabilization of autotransplanted teeth. Because rigid or extended fixation periods can cause complications such as ankylosis and disturbances of pulpal revascularization, our aim was to evaluate an alternative technique, a removable splint, for improving the success rate of autotransplanted molar teeth.

Study Design: In 44 patients, (20 male and 24 female patients), 45 transplanted teeth were analyzed. These cases were followed for 31 to 47 months after operation. Transplanted teeth were evaluated after use of a thermoplastic retainer for 1 month, in terms of success rate and dissatisfaction with this apparatus. The primary stability, ankylosis, and root resorption were also analyzed.

Results: To date, 1 transplant was extracted after 6 months due to unpreventable periapical root inflammation, and 2 transplants were extracted after one year due to external root resorption. Although 2 ankylosed transplants were still functional after an average follow-up period of three years, with no dissatisfaction by the patients, these cases were treated as failures because of the probable risk for external root resorption. The remaining $40(88.8 \%$ success rate) transplants remained asymptomatic and functioning for a mean follow-up period of 37 months. In the assessment of dissatisfaction with the thermoplastic retainer, $36(81.8 \%)$ patients had no or little dissatisfaction, 4 (9\%) patients had very appreciable or excessive dissatisfaction, and $4(9 \%)$ patients had moderate dissatisfaction. Conclusions: A thermoplastic retainer for use after autotransplantation of third molar teeth is a reasonable and useful method and a good alternative to conventional rigid or semi-rigid splints. This technique was especially useful in autotransplanted teeth that had poor stability, i.e., in cases in which it is conventionally advised to use long-term rigid or semi-rigid splints.
\end{abstract}

Key words: Autotransplanted third molar teeth, thermoplastic retainer, splinting. 


\section{Introduction}

Autogenous tooth transplantation for replacement of lost molars is now an accepted and reliable alternative to conventional prosthetic therapy or implants $(1,2)$. It is an effective modality for replacing missing teeth when a donor tooth is available and is generally advised in cases of teeth lost prematurely due to trauma, caries, periodontal disease, dental agenesis or nontreatable root fractures (3). The survival rate of autogenously transplanted teeth varies from $68 \%$ to $100 \%(3,4)$.

A number of different techniques for tooth autotransplantation have been reported. The prognosis for autotransplantation is related to several factors, including careful manipulation of the root and socket, postoperative maintenance, and stabilization of the transplanted tooth (5).

Numerous splinting techniques have been suggested for postoperative transplant stabilization, including fixation with orthodontic appliances, ligature wires, acidetch composites, and sutures (5).

The stabilization time required was between 1 and 4-6 weeks (6). However, excessive fixation time for the transplanted tooth was found to inhibit periodontal regeneration, leading to numerous occurrences of ankylosis, periodontal inflammation, and inflammatory root resorption. Furthermore, rigid splinting has been observed to have adverse effects on the revascularization of the pulp $(6,7)$.

Akkocaoglu et al. (5) assessed the success rate of autotransplanted teeth without stabilization by splints. Initial stability of the transplant was maintained by frictional retention using the adjacent teeth. However, this technique can only be used when transplants have good stability and sufficient mesiodistal width. Sometimes (especially when primer retention cannot be achieved) splinting is obligatory when transplants are small according to mesiodistal size (6).

Considering that splinting is necessary for many transplants, especially cases with poor stability, as well as the disadvantage of rigid spIints, we used removable, non-rigid splints in the present study. Our aim was to evaluate the efficacy of a thermoplastic retainer in terms of success rate of autotransplanted molar teeth. We also evaluated thermoplastic retainers according to complaints by patients.

\section{Patients and Methods}

This retrospective study was comprised 56 transplanted teeth in 55 patients consecutively admitted for eventual autotransplantation after extraction of a molar tooth. Of these, 11 patients were excluded from the study as 6 failed to return for follow-up evaluations, 3 did not report for root canal treatment appointments on time, and 2 patients were discontinued for protocol violation as they failed to use the thermoplastic retainer. Of the remaining, 45 transplanted teeth in 44 patients (20 male and 24 female patients) were included in this study. In one patient, two teeth were transplanted. At the time of transplantation, the average age of patients was 23.14 years, ranging from 16-39 years. The patients were treated by the same surgeon and one endodontic specialist during period of 2005-2009. The patients were fitted with thermoplastic retainers by two different prosthodontists. The donor teeth and recipient sites are presented in Table 1. Informed consent for therapy was obtained from all of the patients.

The receiving sites were sockets of teeth that had been extracted because of caries, periodontal or periapical infection, root fracture, or iatrogenic injury from root canal reamers.

The mesiodistal size of the donor tooth and the recipient site were carefully evaluated on panoramic radiography and periapical radiographs taken with a parallel technique. If the probability of removing the transplant with preservation of the root cement was considered to be good and if the transplant had a suitable shape and dimension for the recipient site, the patient was included in the study.

Most of the transplants in this study were closed apex transplants: 34 closed apex and 11 open apex. The inclusion criterion for transplant with an open apex was at least half root development. Atraumatic surgical removal of the third molar was essential, preserving the root sheath and apical portion of the developing tooth bud.

The patients were controlled by the same surgeon and periodontologist. The transplants were assessed according to color, mobility, position, and abnormal percussion sounds that might indicate ankylosis or other pathosis. The form of gingival tissue was inspected, and gingival crevices were probed to evaluate periodontal attachments and root surfaces. The lack of periodontal ligament area on radiography and perception of a metallic percussive sound was considered to be an indication that the tooth had ankylosed.

Success was categorized as: (1) normal periodontal healing; (2) lack of any inflammation pulpal changes or progressive external or internal root resorption; (3) nonankylosis; (4) continued development of root growth (5) physiological mobility. If any one of these criteria was not met, the case was recorded as a failure.

All patients were treated under local anesthesia. The flap of the recipient area was reflected, and the recipient bone was carefully contoured using a high-speed handpiece with surgical bur, with copious saline irrigation. Any dental remnants left at the recipient site were removed. The transplant was carefully extracted and transferred to the prepared alveolus. Care was taken to keep the root surface moist throughout the extraoral procedures. The transplant was ensured to be in a proper occlusion (preferably with $1 \mathrm{~mm}$ below the occlusal 
contact). In the normal condition, the buccal aspects of the transplant were placed buccally but, if necessary (especially due to lack of space), the transplant was rotated 180 degrees. The donor tooth sometimes had to be adjusted with a rotating diamond bur in order to fit the recipient site.

For all transplanted teeth, preoperative antibiotic prophylaxis with $2 \mathrm{~g}$ amoxicillin/clavulanic acid and postoperative management including systemic antibiotics (625 mg amoxicillin/clavulanic acid) was performed BID for 5 days. Mouth rinses (chlorohexidine gluconatebenzydamine HCL) TID for seven days and an analgesic (naproxen sodium $550 \mathrm{mg}$ ) BID for seven days per orally were prescribed.

An endodontic treatment was performed on all closed apex transplants, extraorally or intraorally. Intraoral root canal treatment of transplanted teeth was started within 2 weeks after operation.

Before operation, the root length of the transplants was judged by radiographic examination. The primary sta- bility was defined with respect to whether the donor tooth was well fitted in the recipient site without severe mobility. The poor stability group constituted of transplanted teeth that were poorly adapted to the recipient site and exhibited great mobility.

Ankylosis was diagnosed based on the findings of periodontal ligament loss on radiographs, and a metallic sound.

For protection against occlusal and lateral forces of the transplanted teeth, a thermoplastic retainer (Fig.1 A-B) was applied to all patients. The patient had not been using any other rigid or semi-rigid splints. The thermoplastic retainer was continuously used for an average of 1 month. Patients were asked not to remove the apparatus unless in the course of tooth and apparatus cleaning.

Patients were asked to assess their dissatisfaction with the thermoplastic retainer $(0=$ no, $1=$ little, $2=$ moderate 3 =very much, 4=excessive), with satisfied classed as patients with a 'no' or 'little' rating and dissatisfied classed as patients with a 'very much' or 'excessive' rating.

Table 1. Distribution of transplanted third molars according to donor and recipient sites.

\begin{tabular}{|l|c|c|c|c|c|c|}
\cline { 3 - 7 } \multicolumn{2}{c|}{} & \multicolumn{3}{c|}{ Recipient Site } & \multicolumn{2}{c|}{} \\
\hline Donor third molar & 16 & 26 & 36 & 37 & 46 & 47 \\
\hline Maxillary right & 5 & 1 & 1 & - & 1 & - \\
\hline Maxillary left & 2 & 4 & 2 & 1 & 1 & - \\
\hline Mandibular left & - & - & 6 & 3 & 3 & 1 \\
\hline Mandibular right & - & - & 3 & 1 & 6 & 4 \\
\hline Total & 7 & 5 & 12 & 5 & 11 & 5 \\
\hline
\end{tabular}

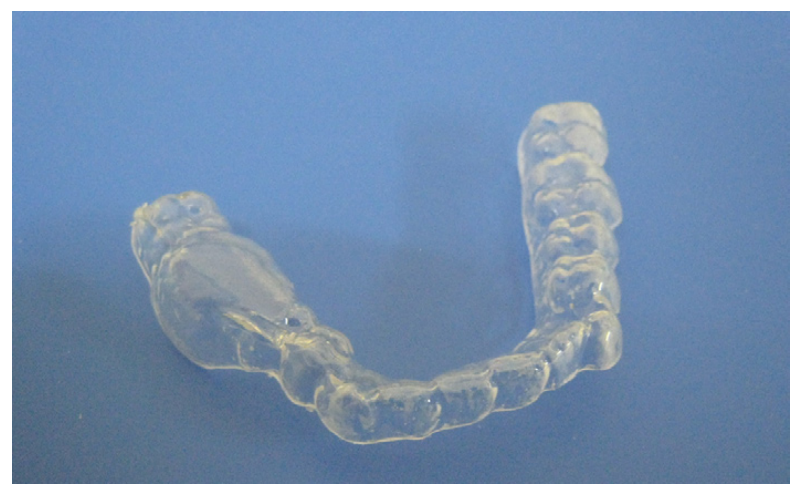

Fig. 1. A) Thermoplastic retainer.

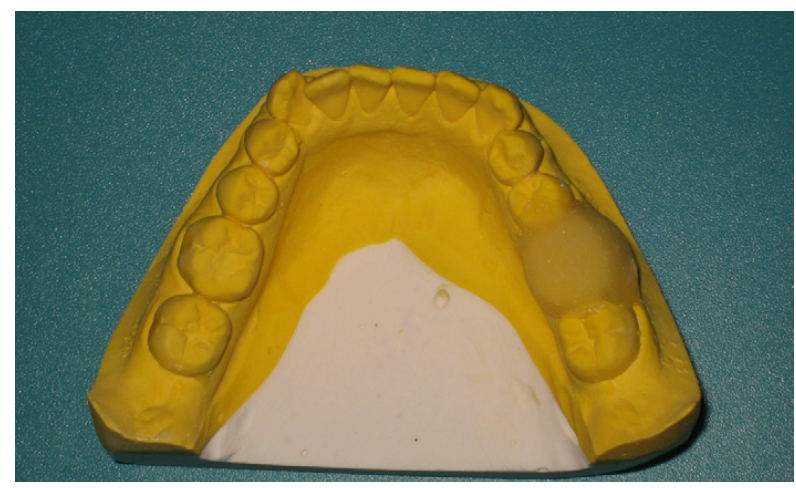

Fig. 1. B) For protection of transplanted tooth the mold was blocked out. 


\section{Results}

Among the 45 cases evaluated, one transplant was followed for 6 months and then extracted due to unpreventable periapical root inflammation, and 2 transplants were extracted after 1 year due to external root resorption (Fig. 2). During the follow-up period, clinical and radiographic evaluation revealed evidence of ankylosis in two teeth. After an average three year follow-up period, these ankylosed transplants were still functional. However, for the purposes of this study, they were accepted as failures. Table 2 shows the results of failed and ankylosed tooth analysis. Therefore, 40/45 autotransplantations were successful and the overall survival rate was $88.8 \%$ during the follow-up period. All transplants are still under our maintenance program. (An example of successful case showed Figs. 3 A, B, C).

The postoperative follow-up period for successful transplants ranged from 31 to 47 months, with a mean of 37 months. In all successful cases, a continuous periodontal space was present radiographically around the transplanted third molar at 6 months after surgery. Progressive root resorption was not found in the follow-up period.

-Effect of primary stability of donor tooth

Initial stability at the recipient site of the transplant was good in 28 cases and poor in 17 cases (Table 3). Among these 28 cases with good stability, complete healing was observed in $24(85.7 \%)$ cases, ankylosis in $2(7.1 \%)$ cases, and failure $2(7.1 \%)$ cases. Among the 17 cases with poor stability, complete healing was observed in 16 $(94.1 \%)$ cases and failure in $1(5.9 \%)$ case. All transplants (except the failed tooth due to apical inflammation) had achieved desirable stability by 3 months after the procedure.

\section{-Extraoral time}

Extraoral time of 45 transplants ranged from immediately after extraction to $40 \mathrm{~min}$, with a mean of $13.28 \mathrm{~min}$. The mean extraoral time of the 16 transplants that underwent intraoral endodontic treatment was $19.68 \mathrm{~min}$. In the 18 patients who underwent extraoral endodontic treatment, the mean extraoral time was $7.96 \mathrm{~min}$.

The extraoral times of the ankylosis cases were 10 and $40 \mathrm{~min}$, with a mean of $25 \mathrm{~min}$. The extraoral times of 2 cases with external root resorption were 15 and $13 \mathrm{~min}$, with a mean of $14 \mathrm{~min}$.

\section{-Effect of root canal treatment}

Transplants with an open apex were all successful and none of these required root canal treatment. Among the root canal treatment group, 18 of the transplants underwent extraoral root canal treatment and 16 of the transplants underwent intraoral root canal treatment. Both ankylosis cases were observed in transplant cases where the treatment had been extraoral. One of the external root resorption cases was seen in the extraoral root canal treatment group and the other was seen the intraoral root canal treatment group.

The failure case with periapical root inflammation was seen in the intraoral root canal treatment group.

Assessment of dissatisfaction with the thermoplastic retainer

Patient assessment of their satisfaction with the thermoplastic retainer revealed a greater percentage of patients who were satisfied (no or little dissatisfaction) compared with dissatisfied patients (very much or excessive dissatisfaction) (36 [81.8\%] vs. 4 [9\%], respectively). Only 4 patients $(9 \%)$ had moderate dissatisfaction with the thermoplastic retainer. The main complaints of patients were difficulty chewing, gingival tissue injuries, and difficulties in adaptation.

Table 2. The analysis of failed and ankylotic cases.

\begin{tabular}{|c|c|c|c|c|c|l|l|}
\hline $\begin{array}{l}\text { Case } \\
\text { no }\end{array}$ & $\begin{array}{l}\text { Tooth } \\
\text { no }\end{array}$ & Age & Sex & $\begin{array}{l}\text { Extraoral } \\
\text { time }\end{array}$ & $\begin{array}{l}\text { Primary } \\
\text { stabilite }\end{array}$ & Possible cause of failure & $\begin{array}{l}\text { Final } \\
\text { situation }\end{array}$ \\
\hline 1 & 46 & 31 & $\mathrm{M}$ & 15 & Good & $\begin{array}{l}\text { Inappropriate root canal } \\
\text { treatment }\end{array}$ & $\begin{array}{l}\text { External } \\
\text { resorption }\end{array}$ \\
\hline 2 & 46 & 22 & $\mathrm{M}$ & 13 & Good & Unknown & $\begin{array}{l}\text { External } \\
\text { resorption }\end{array}$ \\
\hline 3 & 46 & 25 & $\mathrm{M}$ & 40 & Good & Extended extraoral time & Ankylosis \\
\hline 4 & 47 & 27 & $\mathrm{~F}$ & 15 & Good & $\begin{array}{l}\text { Inappropriate root canal } \\
\text { treatment due to obstructed } \\
\text { root canal }\end{array}$ & $\begin{array}{l}\text { Unpreventable } \\
\text { periapical } \\
\text { inflammation }\end{array}$ \\
\hline 5 & 26 & 21 & $\mathrm{~F}$ & 10 & Good & Unknown & Ankylosis \\
\hline
\end{tabular}




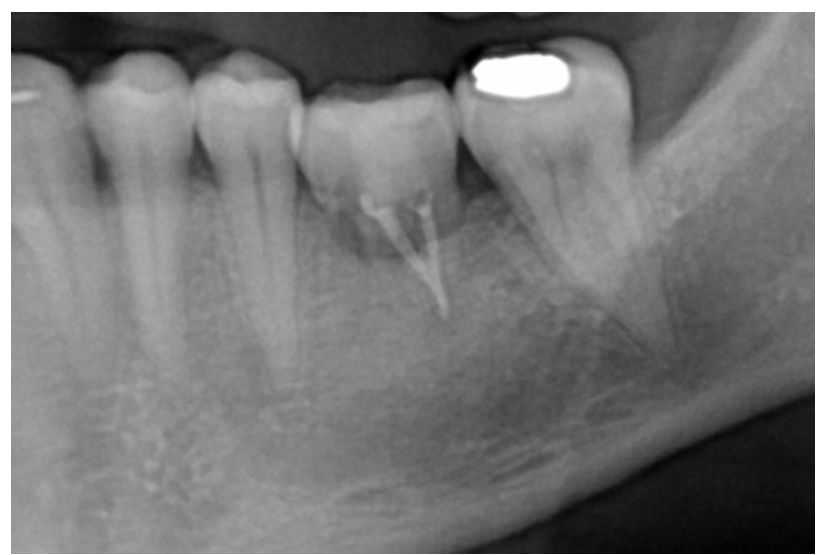

Fig. 2. Radiographic view of external resorption in an autotransplanted tooth.

Table 3. Primary stability effect of success on transplanted third molar teeth.

\begin{tabular}{|l|c|c|c|}
\cline { 2 - 4 } \multicolumn{1}{c|}{} & Ankylosis & Complete healing & Failed \\
\hline Good stability & 2 & 24 & 2 \\
\hline Poor stability & - & 16 & 1 \\
\hline
\end{tabular}

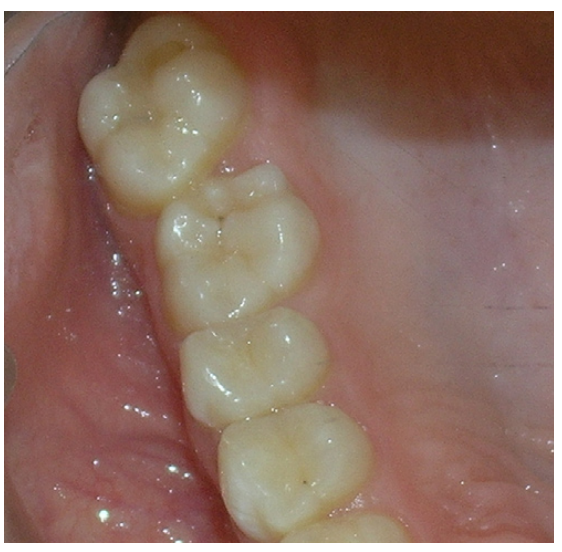

Fig. 3. A) An example of complete healing. Intraoral appearance of maxillary right first molar transplanted tooth.

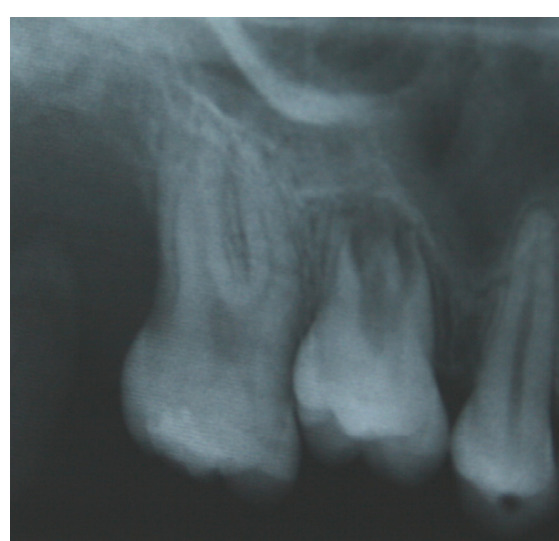

Fig. 3. B) Radiographic appearance of this tooth 3 months after operation.

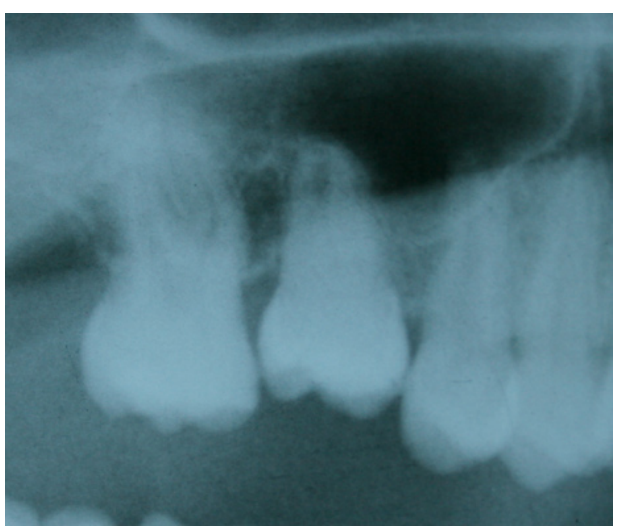

Fig. 3. C) Radiographic appearance of transplant after 38 months. 


\section{Discussion}

Autotransplantation is not a common procedure in clinical dental practice, but can be a viable method for restoring missing teeth or lost alveolar bone areas. Transplantation of teeth with both open and closed apexes of root formation are considered to be comparatively simple procedures with high success rates (8). Although there is probability of some complications, such as external or internal root resorption, ankylosis, unpreventable pulpal or periapical infection, or endodontic complications, autotransplantation has several advantages over dental implants and other prosthetic approaches, in consideration of normal periodontal healing, proprioceptive function, natural chewing feeling, and natural biological responses. Moreover, autotransplantation can preserve the continued alveolar bone induction in growing children (9).

A number of factors are vital for the success of tooth autotransplantation, including good general health of the patients, the surgical technique of the operator, adequate space preparation at the recipient site, extraoral handling time, vital ligament cells on the root, splinting with adequate fixation and sufficient duration, endodontic technique, and the maintenance of good oral hygiene $(10,11)$. In addition, when provided within an interdisciplinary team, transplants can be a highly successful long-term option with a good esthetic outcome (12). For this reason, in the present study, all cases were assessed by a team of doctors consisting of surgeons, prosthodontists, and periodontic and endodontic specialists.

Successful criteria for autotransplantation are normal periodontal healing (pocket depths, gingival contour, and color are within normal limits), absence of inflammatory pulpal changes or inflammatory root resorption, tooth mobility that is within physiologic range, without any bleeding on probing and achievement of satisfactory masticatory functions (10). In radiographic analysis, the criteria are a visible lamina dura, no apparent pathologic condition, and evidence of further growth of the root of immature teeth (7).

Although some reports have suggested that even if root formation of donor teeth is not completed, the success rates of transplantation are excellent, there are many other reports that have demonstrated that endodontically treated donor teeth with closed apexes are also reliable $(4,13,14)$. Teeth with one-third to three-quarter root formation are most frequently transplanted clinically (8). In the present study, teeth with at least halfroot formation were transplanted in the incomplete root formation group.

Preservation of the periodontal ligament is vital for the success of tooth autotransplantation. Satisfactory healing of the periodontal ligament (PDL) depends on reorganization of periodontal fibres $(7,10)$. Thus, donor teeth have to be extracted with minimal mechanical damage to the periodontal ligament cells. Tissue adaptation is also crucial for the maintenance of healthy periodontal ligament cells. Care was taken to maintain the periodontal ligament when extracting all donor teeth. Periodontal ligament cells also adversely affected the duration of extraoral time of the donor tooth, which can cause undesirable results such as inflammation or root resorption (14). In the present study, the mean extraoral time was $13.2 \mathrm{~min}$. In one of the two cases that developed ankylosis, extraoral time was $40 \mathrm{~min}$, which suggested that this ankylosis case was linked to the longer extraoral time.

Some transplants cannot be fitted reasonably well into the recipient site. Although 17 cases had poor stability in the present study, 16 of these healed successfully. Therefore, we can assume that the thermoplastic retainer was effective for the protection transplanted teeth against early occlusal and lateral forces, especially those transplants with poor stability.

The available literature describes many different stabilization techniques for transplanted teeth, including fixation with orthodontic brackets, ligature wires, acidetch composites, and sutures $(1,5,6)$. The stabilization period for transplanted teeth varies between one and 4-6 weeks (6). Increased duration of immobilization periods can negatively influence the periodontal regeneration, causing numerous complications such as ankylosis and inflammatory root resorption. Moreover, use of a rigid splint has shown a negative influence on the revascularization of the pulp. There are many reports which have advised a suture splinting period of 7-10 days, but this technique was proposed only in cases with good primary stability, while rigid fixation for 4 weeks is seen in cases with poor initial stability $(6,7)$.

In contrast to these techniques, Akkocaoğlu et al. (5) indicated that autotransplantation of teeth without primary splint stabilization was a reliable treatment. Their cases were restricted only to well-fitted transplantations. Stabilization of transplants was provided by frictional retention with the neighboring teeth. However, we know that appropriate fixation is especially vital for transplants with poor stability.

Optimal contact of the transplant with the alveolar bone of the recipient site can improve the blood supply and the level of nutrition to the periodontal ligament cells, thus increasing the number of viable cells $(8,14)$. However, optimal contact cannot be provided every time. Long-term splinting should be used in cases where the primary stability is not good, but this increases the risk of ankylosis. This type of case was considered as particularly appropriate for the use of thermoplastic retainers.

The thermoplastic retainer was first described by Ponitz (15) in 1971 as an alternative to the traditional removable retainer. This type of retainer is durable, aesthetic, easy 
to clean, and inexpensive. This retainer is now commonly used by orthodontists and prosthodontists for a number of different purposes (16). In the present study, this type of retainer was used as a removable splint for protection of transplanted third molar teeth against lateral and occlusal forces. Considering the disadvantages associated with the rigid fixation that is mandatory for transplants with poor stability, the use of thermoplastic retainers was considered to be a reasonable option for stabilization of transplanted teeth in the present study. Because there is a probability that discomfort can be encountered with patient use of thermoplastic retainers, we also needed to evaluate this retainer in terms of patient dissatisfaction. A greater percentage of patients $(81.8 \%)$ were satisfied but $9 \%$ of patients were dissatisfied with this retainer.

Based on the literature, $96 \%$ of teeth with open apexes and $15 \%$ of teeth with closed apexes can be revitalized. Thus, transplants with incomplete root formation are not recommended for root canal treatment (8). Considering transplants with closed apexes, some reports (10) have suggested that endodontic treatment is necessary within 3 to 4 weeks. However, according to The American Association of Endodontists, teeth should be extirpated between 7 and 14 days after operation to prevent infected necrotic pulp, which can cause external or internal resorption and early loss (8). In this study, no endodontic treatment was performed on any transplant with an open apex and all of the transplanted teeth were successfully healed. Transplants with closed apexes were treated intraorally or extraorally by root canal treatment. Endodontic consultation was made for the choice of which root canal treatment option was implemented. Those cases that were thought to be difficult to treat endodontically after transplantation, for example; dilacerated or curved roots, were treated extraorally. Periapical inflammation was encountered only in one case, which was treated by intraoral root canal treatment.

The success rate of tooth transplantation is varied: Akkocaoğlu and Kasaboğlu (5) 96 transplanted teeth, $86 \%$ success rate, Mejare et al. (1) 50 teeth, $81.4 \%$ success rate, Jonsson et al. (17) 40 teeth, $92.5 \%$ success rate, Pogrel (18) 416 teeth, $72 \%$ success rate, Slagsvold and Bjercke (19) 34 teeth, $100 \%$ success rate. These results are in accordance with our present results. In our study, one tooth was extracted due to unpreventable periapical inflammation and 2 cases were extracted due to excessive external resorption. Although the two teeth that presented clinical signs of ankylosis were still functional and patients were satisfied with these teeth, they were accepted as failures for the purposes of this study. It is generally agreed that a gradual, progressive resorption of the tooth can be prospected with ankylosis (20). Thus, the overall survival rate was $88.8 \%$.

\section{Conclusions}

This study supports the hypothesis that use of a thermoplastic retainer for autotransplantation (especially in cases poor initial stability) could be a reasonable alternative to conventional rigid or semi-rigid splints. However, we cannot suggest that these are superior to other splints in terms of preventing ankylosis.

\section{References}

References with links to Crossref - DOI

1. Mejàre B, Wannfors K, Jansson L. A prospective study on transplantation of third molars with complete root formation. Oral Surg Oral Med Oral Pathol Oral Radiol Endod. 2004;97:231-8.

2. Waikakul A, Kasetsuwan J, Punwutikorn J. Response of autotransplanted teeth to electric pulp testing. Oral Surg Oral Med Oral Pathol Oral Radiol Endod. 2002;94:249-55.

3. Herrera H, Herrera H, Leonardo MR, de Paula e Silva FW, da Silva LA. Treatment of external inflammatory root resorption after autogenous tooth transplantation: case report. Oral Surg Oral Med Oral Pathol Oral Radiol Endod. 2006;102:e51-4.

4. Reich PP. Autogenous transplantation of maxillary and mandibular molars. J Oral Maxillofac Surg. 2008;66:2314-7.

5. Akkocaoglu M, Kasaboglu O. Success rate of autotransplanted teeth without stabilisation by splints: a long-term clinical and radiological follow-up. Br J Oral Maxillofac Surg. 2005;43:31-5.

6. Bauss O, Zonios I, Engelke W. Effect of additional surgical procedures on root development of transplanted immature third molars. Int J Oral Maxillofac Surg. 2008;37:730-5.

7. Teixeira CS, Pasternak B Jr, Vansan LP, Sousa-Neto MD. Autogenous transplantation of teeth with complete root formation: two case reports. Int Endod J. 2006;39:977-85.

8. Mendes RA, Rocha G. Mandibular third molar autotransplantation-literature review with clinical cases. J Can Dent Assoc. 2004;70:761-6.

9. Demir T, Ates U, Cehreli B, Cehreli ZC. Autotransplantation of a supernumerary incisor as a replacement for fused tooth: 24-month follow-up. Oral Surg Oral Med Oral Pathol Oral Radiol Endod. 2008;106:e1-6.

10. Arikan F, Nizam N, Sonmez S. 5-year longitudinal study of survival rate and periodontal parameter changes at sites of maxillary canine autotransplantation. J Periodontol. 2008;79:595-602.

11. Rao J, Fields HW, Chacon GE. Case report: autotransplantation for a missing permanent maxillary incisor. Pediatr Dent. 2008;30:160-6.

12. Day P, Duggal M. Autotransplantation for failing and missing anterior teeth. Pediatr Dent. 2008;30:286-7.

13. Kitahara T, Nakasima A, Shiratsuchi Y. Orthognathic treatment with autotransplantation of impacted maxillary third molar. Angle Orthod. 2009;79:401-6.

14. Kim E, Jung JY, Cha IH, Kum KY, Lee SJ. Evaluation of the prognosis and causes of failure in 182 cases of autogenous tooth transplantation. Oral Surg Oral Med Oral Pathol Oral Radiol Endod. 2005;100:112-9.

15. Ponitz RJ. Invisible retainers. Am J Orthod. 1971;59:266-72.

16. Thickett E, Power S. A randomized clinical trial of thermoplastic retainer wear. Eur J Orthod. 2010;32:1-5.

17. Jonsson T, Sigurdsson TJ. Autotransplantation of premolars to premolar sites. A long-term follow-up study of 40 consecutive patients. Am J Orthod Dentofacial Orthop. 2004;125:668-75.

18. Pogrel MA. Evaluation of over 400 autogenous tooth transplants. J Oral Maxillofac Surg. 1987;45:205-11.

19. Slagsvold O, Bjercke B. Autotransplantation of premolars with partly formed roots. A radiographic study of root growth. Am J Orthod. 1974;66:355-66.

20. Czochrowska EM, Stenvik A, Bjercke B, Zachrisson BU. Outcome of tooth transplantation: survival and success rates 17-41 years posttreatment. Am J Orthod Dentofacial Orthop. 2002;121:110-9. 